\title{
Challenges, constraints and solutions for modeling regional-scale dispersal of invasive organisms: from practice to policy
}

\author{
$\underline{\text { R.D. van Klinken }}^{\text {a }}$ and J. Murray ${ }^{\text {a }}$ \\ ${ }^{a}$ CSIRO Ecosystem Sciences (EcoSciences Precinct, Brisbane) \\ Email: rieks.vanklinken@csiro.au
}

\begin{abstract}
Invasive organisms can cause dramatic impacts to a wide range of stakeholders. Once established within a country their management is most often resourced and implemented at local to regional scales. Predicting the dispersal potential of these key organisms is central to effective management. For example, management actions include early detection and eradication of new outbreaks, and the establishment and maintenance of containment lines, both of which require a good spatial understanding of invasion risk. We present modeling work which seeks to predict the spread of the invasive pasture weed parthenium (Asteraceae; Parthenium hysterophorus) in the Queensland Murray Darling Basin, with the aim of helping natural resource management agencies to best target their resources. This is part of a broader modeling program aimed at developing generic spatial modeling approaches for invasive organisms. A Bayesian Belief Network capturing the key drivers of distribution and dispersal was developed during an expert elicitation workshop and subsequently linked to relevant environmental layers within GIS. The models combined predictions of habitat suitability (where the plant will do well given the opportunity) and introduction risk (the risk of arrival of propagules from known sources) to probabilistically predict habitat susceptibility. Models predicted dispersal and spread within a 10 year time-frame to account for inter-annual stochasticity in some key environmental variables and vectors (e.g. major flood events). Multiple vectors were important and these were grouped as local "incidental" dispersal, water dispersal and long-distance transport. However, process knowledge of dispersal typically outstripped the spatial data on vector movement required to implement the models. We discuss how these and other challenges and constraints were dealt with, and how the resulting model predictions helped inform policy and management.
\end{abstract}

Keywords: Bayesian Belief Networks, expert elicitation, GIS, invasive plants, habitat suitability modeling, long-distance dispersal, Parthenium hysterophorus 
van Klinken and Murray, Challenges, constraints and solutions for modeling regional-scale dispersal of invasive organisms: from practice to policy

\section{INTRODUCTION}

Invasive organisms continue to pose a serious threat to our environment, economy and society. A key management response is to prevent new incursions, or to rapidly contain and eradicate new incursions when they are found. This is relevant at a range of scales. At the national scale border protection aims to keep potentially serious invaders out of the country, or to eradicate them if they do occur. Once invasive organisms become widely established then resources are typically spent at regional scales to prevent further spread and impact of weeds (Thorpe \& Lynch, 2000, Martin \& van Klinken, 2006). Predicting the potential spread of invasive organisms is therefore important for identifying future risks, and for designing surveillance, eradication, containment and asset protection responses.

Considerable research has been conducted into spatially predicting the spread of invasive organisms, including weeds. Most approaches superimpose a dispersal model over an existing habitat suitability model (Gallien et al., 2010) to predict habitat susceptibility. Dispersal models vary, but include individual based models (Molofsky, 1994, Travis \& Dytham, 1998, Dytham, 2003) or dispersal kernels (Nathan \& Muller-Landau, 2000, Nathan, 2006, Nathan 2007; Coutts et al., 2011). However, application of these models to predict weed spread in real environments is typically faced with a range of uncertainties. Attention has been given to difficulties in describing the shape of dispersal kernels, especially in terms of describing the tail of the dispersal kernel (longdistance dispersal) (Nathan, 2006). However, other uncertainties include knowing which vectors are important, and their relative role in spread. The contribution to dispersal of multiple vectors can be described within a "total dispersal kernel" (Nathan, 2007), although this does not consider the fact that movement behaviour of specific vectors is typically dependent on the context in which they occur, and can vary through time. For example, seed dispersal by water is highly sensitive to landscape position, and inter-annual variation in flooding (Truscott et al., 2006, Lopez \& Kursar, 2007).

In this paper we present an evolving approach to modeling weed dispersal and habitat susceptibility at the regional scale for the purposes of assisting in prioritizing limited weed management resources. We rely on expert elicitation to identify the main spread vectors, their relative importance for weed spread, and how they move seed (distance and direction) through the landscape. This expert knowledge is formalized within a Bayesian Belief Network before linking it to relevant spatial environmental data to predict spread within the target region. Modeling is conducted in collaboration with the end-users to ensure ownership and application of key findings. This is a general approach that we have already applied to several weeds, but we present an overview of work conducted on one annual pasture weed species, Parthenium hysterophorus (Asteraceae) or "parthenium", in the Queensland Murray Darling Basin (QMDB). Parthenium has been nominated as one of twenty weeds of national significance (Thorpe and Lynch 2000). The national management strategy currently seeks to contain it to central Queensland, with the southern containment line running east-west through the QMDB region (QMDC, 2011). It was originally introduced into Australia in 1955 from the USA as a contaminant of grass seed, and extensive areas are infested to the north of the QMDB (Weeds Australia, 2003).

\section{METHODS}

We developed a conceptual model to map weed susceptibility, where we could integrate expert opinion and field data in a spatially-explicit and mechanistic approach (Figure 1). Model outcomes are directed at giving policy makers and management bodies an informed basis for determining the risk of spread of invasive weed species. We used this model to map parthenium risk within the QMDB with the purpose of informing the weed management strategy within that region.

An expert elicitation workshop was held in Mitchell (Queensland) in June 2009 to develop a habitat susceptibility model for parthenium in the QMDB. It was attended by one academic, three local or state management officers and six landholders, all with experience in managing or parthenium. The habitat susceptibility model was built within a Bayesian Belief Network (BBN) (Marcot et al., 2006, Norsys Software Corp, 2009) during the workshop. The susceptibility model included a habitat suitability component (see Murray and van Klinken 2010) and an introduction component described in this paper.

Workshop participants defined susceptibility as the risk of a site being invaded by parthenium within a 10 year period based on habitat suitability (where parthenium populations are able to establish and persist assuming seeds are present) and risk of introduction (probability of seed arrival within a 10 year period). Participants were asked to identify the main vectors for parthenium within the QMDB and to define short, medium and long distance dispersal for each. Once the main vectors were identified participants completed conditional probability tables using a structured probability elicitation technique (CTP calculator, Cain, 2001). This process quantifies the risk that seeds are moved by a particular vector across a short, moderate and long distance, and the probability that a site will be susceptible given its degree of habitat suitability and the risk of seed introduction. The completed BBN was subsequently spatialised by linking it within GIS to relevant spatial data sets. 
van Klinken and Murray, Challenges, constraints and solutions for modeling regional-scale dispersal of invasive organisms: from practice to policy

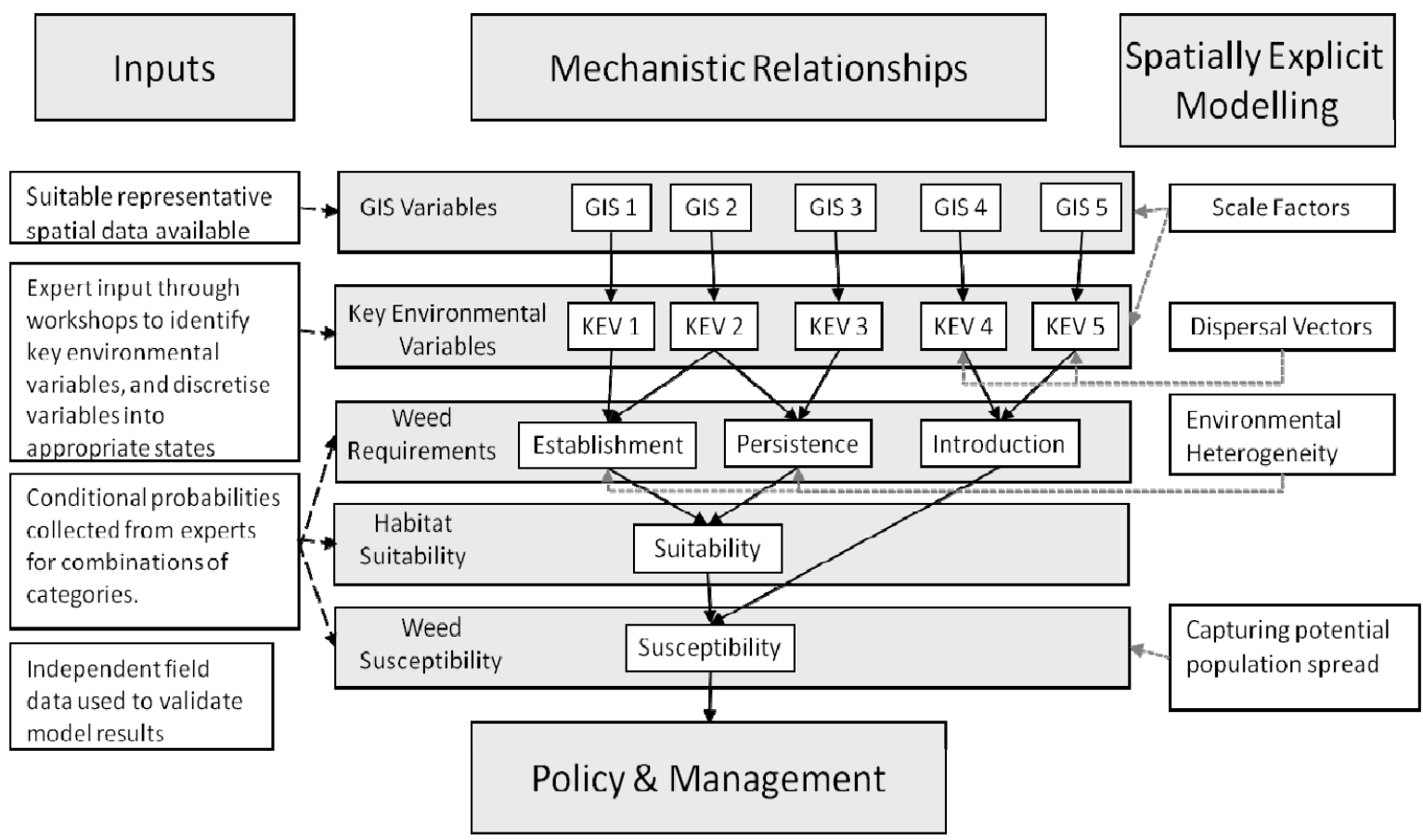

Figure 1: Influence diagram showing model relationship between expert input, capturing mechanistic relationships and spatially explicit modeling to model weed susceptibility for input into policy and environmental management. All information on vectors was obtained through the expert elicitation process.

\section{RESULTS}

The conceptual model allowed us to capture the mechanistic relationships and interactions between variables at different scales. The framework was easily implemented into a Bayes net (Figure 2), which accommodated the main source of information, expert knowledge. Experts with limited statistical backgrounds were able to follow the logic behind developing and populating the BBN and understand the mapped results. The BBN was able to be broken into different components, in this case habitat suitability and introduction, to allow individual expertise to be targeted appropriately. Nodes were also added to examine how different dispersal management strategies impacted model outcomes.

A wide range of dispersal vectors were identified by experts as being important for parthenium. These were modelled as "introduction by flood", "incidental introduction" and "transport" (Figure 2). Introduction by flood considered the probability of seeds moving downstream by a once in ten-year flood event. Several vectors were identified as operating largely at a property-scale, especially wildlife, and on-farm movement of vehicles and livestock. A lack of specific knowledge regarding the relative importance of each vector and their exact movements within the landscape prevented us from modelling them individually, and it also was not critical for regional-scale modelling. Experts therefore decided to consider them together as "incidental introduction" (Figure 2). Introduction by transport modelled distance-dispersal by long-haul vehicles, including through the movement of livestock and produce. This vector is the primary target for containment programs, and disperses seed much further than incidental introduction although at very low probabilities. It was modelled to include the effect of management aimed at reducing the risk of spread by long-distance transport (categorised as partial or stringent, Figure 2). Management options include the use of washdown facilities and avoiding the sourcing of livestock and agricultural products from infested areas. The elicited probabilities of seeds arriving at a site based on vector, distance from known seed source and level of dispersal management is represented in Figure 3.

Sensitivity analysis showed introduction was most influenced overall by introduction by flood, followed by incidental introduction and transport. The child node with the greatest effect was distance downstream from infestation followed by flooding. Stringent transport management reduced the area susceptible to parthenium. 
van Klinken and Murray, Challenges, constraints and solutions for modeling regional-scale dispersal of invasive organisms: from practice to policy

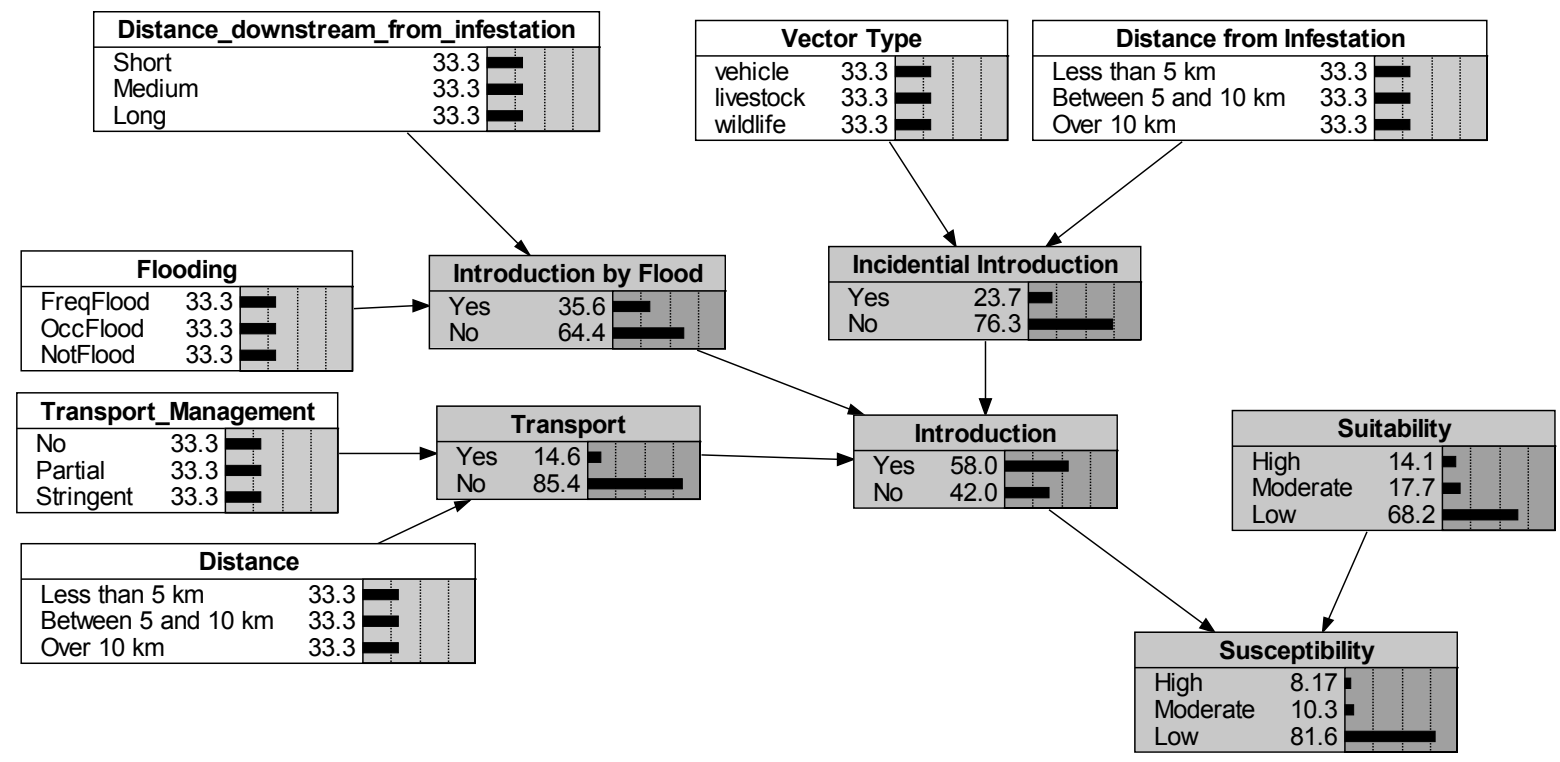

Figure 2: Bayesian belief network developed by elicitation of experts within a workshop environment for susceptibility to the spread of parthenium, focusing on the introduction aspect of the network to capture dispersal. Bayesian networks display the causal relationships (in the form of linked directional arrows) between the key variables (parent nodes) and the effect (child nodes). Probabilities for each parent node (white boxes) display equal likelihood of occurrence. Expert-derived conditional probability tables for every combination are behind each child node (grey boxes) to give likelihoods for each of introduction and susceptibility. 
van Klinken and Murray, Challenges, constraints and solutions for modeling regional-scale dispersal of invasive organisms: from practice to policy

a)

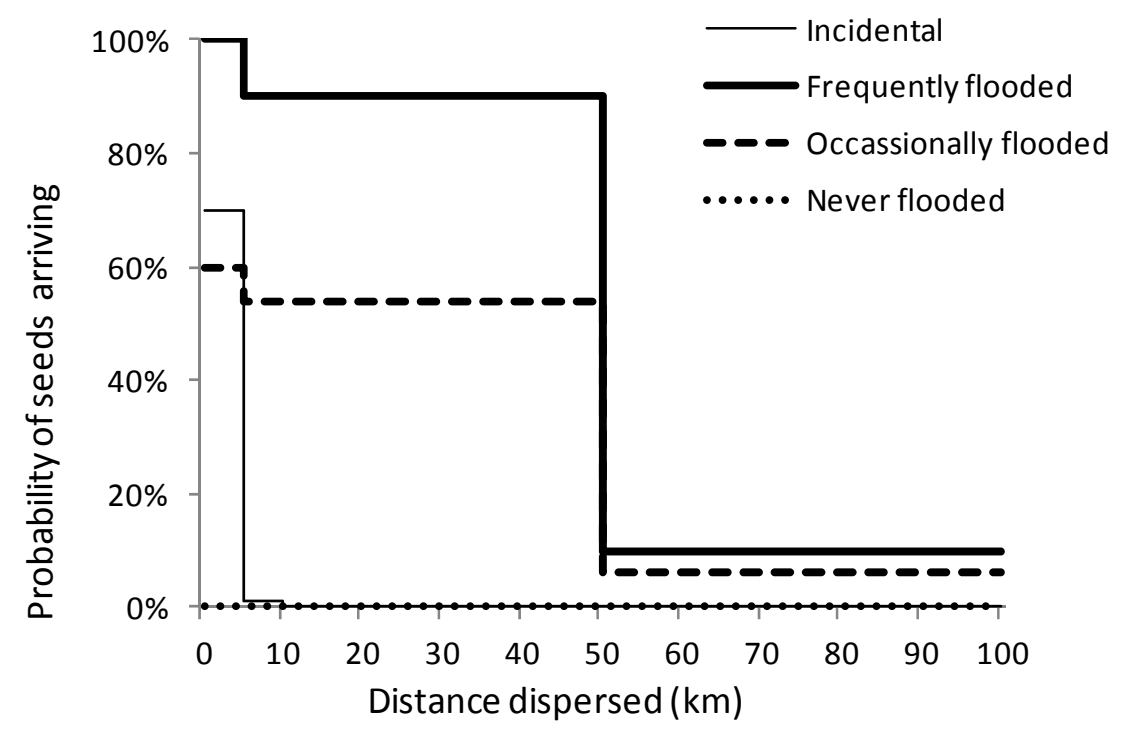

b)

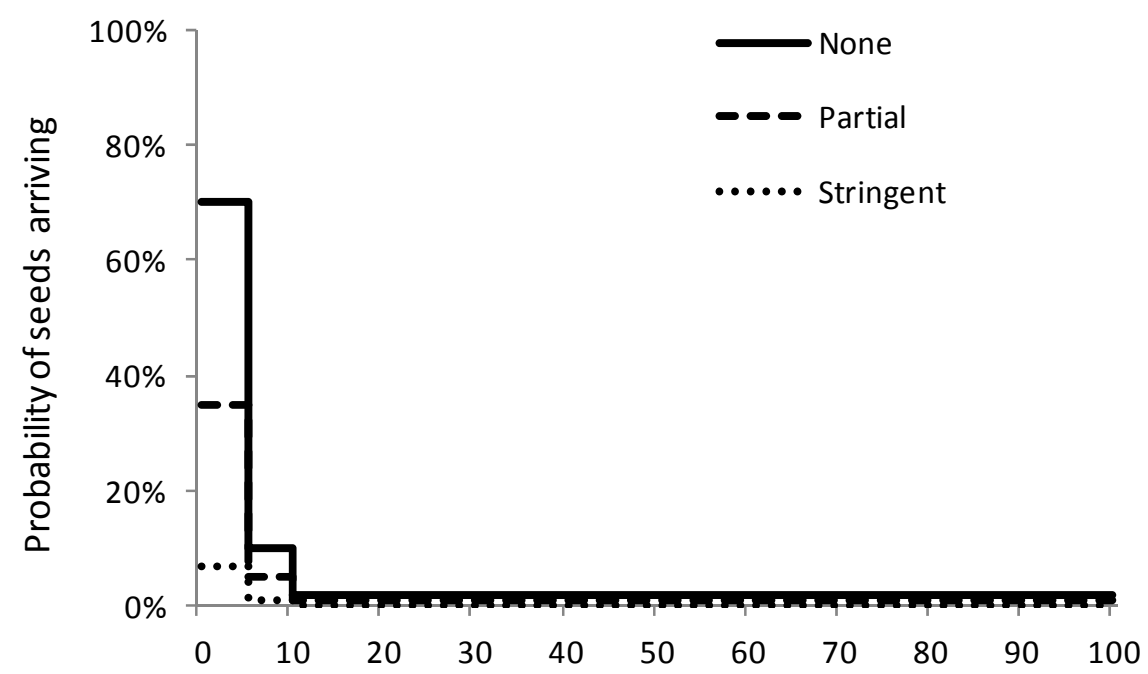

Figure 3: Probability of seeds arriving from a known seed source within a ten year period by flood water and incidental dispersal (a), and by long-distance transport dispersal under different levels of management (b)

Introduction probabilities were low across the region, other than in the vicinity of known populations (Figure 4a). Only a small proportion of highly suitable habitat (Figure 4b) is currently highly susceptible (Figure 4c). Many of the susceptible sites are based on individual parthenium records from PestInfo (Qld DERM captures qualitative shire-level data on major plant and animal pest species biannually from state and local government officers at two scales - local and regional) collected over time, some of which may no longer exist as not all records are continually surveyed. As a consequence the model may therefore overestimate the area that is currently susceptible to parthenium. Conversely, undetected parthenium populations would result in underestimation of habitat susceptibility. Finer spatial resolution shows the contrasting effects the three different vectors has on spread risk (Figures 3d,e,f). 
van Klinken and Murray, Challenges, constraints and solutions for modeling regional-scale dispersal of invasive organisms: from practice to policy
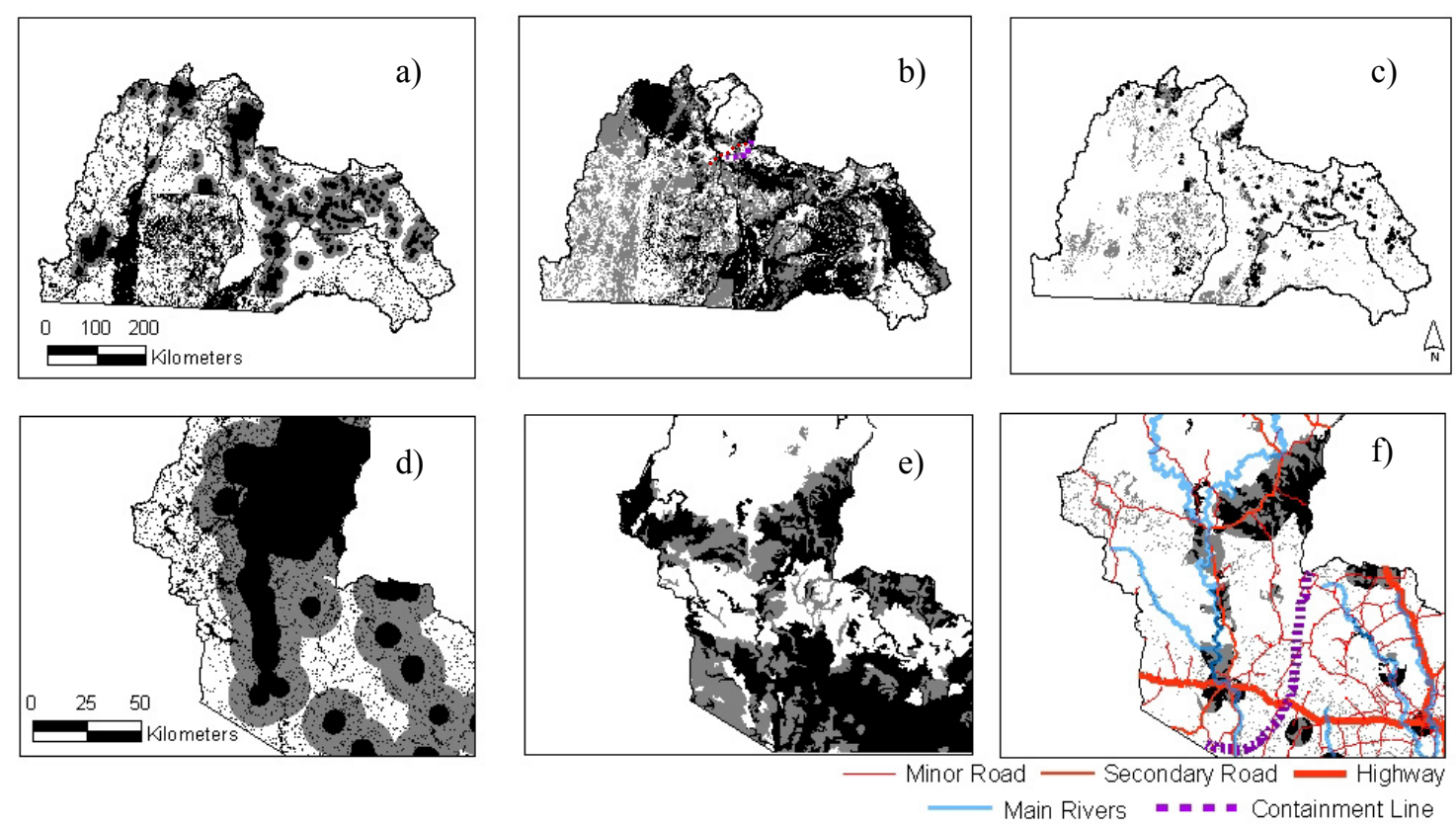

Figure 4: Model results combined with GIS layers to show introduction (a,d), habitat suitability (b,e) and habitat susceptibility (c,f) for parthenium spread. The first row shows the QMDB study area. The second row shows the zoomed northern middle section containing the Maranoa River and the townships of Roma and Mitchell. Black represents high, grey represents moderate and white represents low.

\section{DISCUSSION}

Our modeling suggests that much of the QMDB is susceptible to parthenium invasion. Most of the northern and eastern parts of the region are suitable habitat, there is a high risk of existing incursions spreading locally, and at least a low risk of introduction through long-distance dispersal across the entire region. Low introduction probabilities across the region are consistent with the diffuse distribution of new incursions. Our results therefore suggest that the eventual spread of parthenium through the QMDB is inevitable in the absence of welldirected and ongoing management effort. This highlights the need for rapid identification and response to new incursions and, if possible, efforts to further reduce the already low probability of long-distance dispersal by vehicles.

The different vectors that were identified as being important for parthenium pose very different risks from a management perspective. Managing local dispersal, which can be caused by a wide range of dispersal vectors, will be critical for containing new incursions (Pyšek \& Hulme, 2005, Davies \& Sheley, 2007). A better understanding of the relative importance of different local-scale vectors (wildlife, stock, human movement) is clearly required to determine whether and how such dispersal can be best managed. Dispersal by water is likely to coincide with episodic flood events (Stokes et al., 2010), which were implicitly considered within the 10-year time-frame of our model. From a management perspective dispersal by flood is particularly important where riparian habitats links large areas of suitable habitat that are separated by otherwise unsuitable habitat. It is also especially important in the QMDB as major parthenium infestations lie upstream of as yet largely uninvaded habitat. However, dispersal by long-distance transport clearly poses the greatest threat for new incursions across catchments within the region. It is also the threat that is potentially most effectively addressed through management actions.

Greatly improving the modeling of local dispersal is likely to be difficult owing to the wide range of vectors involved, the likely dependence on local conditions (e.g. land use, landscape configuration, management practices), and the lack of detailed spatial data on key vectors across the region. Any model improvements are also likely to provide the least benefits for developing better regional-scale management strategies. In contrast, improving the modeling of dispersal by long-distance transport is likely to be useful both in terms of minimizing the risk of dispersal, and better identifying areas most at risk of new incursions. Long-distance dispersal in our model is likely to be greatly improved with better knowledge of the relative role of different transport vectors and their movement within the region (Soons et al., 2004, Pyšek \& Hulme, 2005, Veldman \& Putz, 2010). Improvements may be possible through modeling of movement of cropping produce (sunflower seeds), which was recognized as a key vector for parthenium dispersal into New South Wales (Blackmore \& Johnson, 2010). 
van Klinken and Murray, Challenges, constraints and solutions for modeling regional-scale dispersal of invasive organisms: from practice to policy

Also, long-distance cattle movement between areas infested with parthenium and clean areas could be important, and this can now be quantified using nationally-collated electronic ear-tagging data (Durr et al., 2010).

Most weed modeling has been conducted at what can be described as local or landscape scales (Rew \& Cousens, 2001, Buckley et al., 2005, Crossman \& Bass, 2008). Our modeling illustrates both the importance and the inherent difficulties in modeling long-distance dispersal at scales that are relevant for regional-level weed management. The modeling approach we took relied heavily on expert elicitation from a small group of diverse experts with regionally-relevant knowledge. This contrasts with much more mechanistic individual based models or dispersal kernels typically used in dispersal modeling (Soons et al., 2004, Travis et al., 2010, Nathan et al., 2011, Savage et al., 2011). It also relied on existing spatial data sets of environmental variables and vectors, which is the constraint of all spatial modeling (Brambilla et al., 2009). However, it raises the important question as to how to direct investment into improving models in a way that will lead to improved management actions.

Overall our modeling supports the ranking of parthenium as one of the most serious weed threats to the QMBD (V. McDonald pers. comm.), and its ranking as a Weed of National Significance (Thorpe and Lynch 2000). The management implications are still to be considered by collaborators within the Queensland Murray Darling Committee, and by the National Parthenium Management Group. However, the modeling process through expert elicitation workshops has already succeeded in increasing stakeholders understanding and awareness of regional-scale invasion risk of parthenium in the QMDB. We also expect that the model predictions will assist with identifying areas where effort should be directed to improve early detection and response capability, to assist in placing containment lines that will be best assisted by natural habitat and dispersal barriers, and to help focus research effort into further improving risk maps based on better understandings of the most important long-distance dispersal vectors.

\section{ACKNOWLEDGMENTS}

We thank the Queensland Murray Darling Committee, especially Vanessa MacDonald and Darren Marshall, for funding the work and organizing the workshops, and the participants in the expert workshop.

\section{REFERENCES}

Blackmore P.J., and S.B. Johnson (2010). Continuing successful eradication of parthenium weed (Parthenium hysterophorus) from New South Wales, Australia. In: Proceedings of the Seventeenth Australasian Weeds Conference. (ed Zydenbos SM), New Zealand Plant Protection Society. pp.382-385.

Brambilla M., F. Casale, V. Bergero, et al. (2009). GIS-models work well, but are not enough: Habitat preferences of Lanius collurio at multiple levels and conservation implications. Biological Conservation, 142, 2033-2042.

Buckley Y.M., E. Brockerhoff, L. Langer, N. Ledgard, H. North, and M. Rees (2005). Slowing down a pine invasion despite uncertainty in demography and dispersal. Journal of Applied Ecology, 42, 1020-1030.

Cain J. (2001). CPT derivation - Version 1.0.0.

Coutts S.R., R.D. van Klinken, H. Yokomizo, and Y.M. Buckley (2011). What are the key drivers of spread in invasive plants: dispersal, demography or landscape: and how can we use this knowledge to aid management? Biological Invasions, 13, 1679-1661.

Crossman, N.D., and D.A. Bass, (2008). Application of common predictive habitat techniques for post-border weed risk management. Diversity and Distributions, 14, 213-224.

Davies, K.W., and R.L. Sheley (2007).A conceptual framework for preventing the spatial dispersal of invasive plants. Weed Science, 55, 178-184.

Durr P., K. Graham, and S. Eady (2010). GIS mapping of cattle market service areas using the National Livestock Identification Systems (NLIS). Final Report. 68 pp, Australian Biosecurity CRC for Emerging Infectious Diseases.

Dytham, C. (2003). How landscapes affect the evolution of dispersal behaviour in reef fishes: results from an individual-based model. Journal of Fish Biology, 63 (Supplement A), 213-255.

Gallien L, T. Munkemuller, C.H. Albert, I. Boulangeat, W. Thuiller (2010). Predicting potential distributions of invasive species: where to go from here? Diversity and Distributions, 16, 331-342.

Lopez, O.R., T.A. Kursar (2007). Interannual variation in rainfall, drought stress and seedling mortality may mediate monodominance in tropical flooded forests. Oecologia, 2007, 35-43.

Marcot, B.G., J.D. Steventon, G.D. Sutherland, and R.K. Mccann (2006). Guidelines for developing and updating Bayesian belief networks applied to ecological modeling and conservation. Canadian Journal of Forest Research-Revue Canadienne De Recherche Forestiere, 36, 3063-3074. 
van Klinken and Murray, Challenges, constraints and solutions for modeling regional-scale dispersal of invasive organisms: from practice to policy

Martin, T.G., R.D. van Klinken (2006). Value for money? Investment in weed management in Australian rangelands. Rangeland Journal, 28, 63-75.

Molofsky, J. (1994). Population dynamics and pattern formation in theoretical populations. Ecology, 75, 30-39.

Murray, J., and R.D. van Klinken (2010). Modelling landscape susceptibility and impacts for three invasive plants in the Queensland Murray Darling Basin. CSIRO Entomology and CSIRO Healthy Water Ecosystems. 104 pp.

Nathan, R (2006). Long-distance dispersal of plants. Science, 313, 786-788.

Nathan, R, and H.C. Muller-Landau (2000). Spatial patterns of seed dispersal, their determinants and consequences for recruitment. TREE, 15, 278-285.

Nathan, R (2007). Total dispersal kernels and the evaluation of diversity and similarity in complex dispersal systems. Seed Dispersal: Theory and its Application in a Changing World. pp. 252-276. CAB International.

Nathan, R.N.R., G.G. Katul, G. Bohrer, et al. (2011). Mechanistic models of seed dispersal by wind. Theoretical Ecology, 4, 113-132.

Norsys Software Corp (2009). Netica 4.12. Website: http://www.norsys.com. Accessed 10 ${ }^{\text {th }}$ June, 2011.

Pyšek, P, and P.E. Hulme (2005). Spatio-temporal dynamics of plant invasions: Linking pattern to process. Ecoscience, 12, 302-315.

QMDC (2011). Parthenium Rapid Response. Queensland Murray Darling Committee, Website: http://www.qmdc.org.au/projects/parthenium-rapid-response.html. Accessed: 20th July, 2011.

Rew, L.J., and R.D. Cousens (2001). Spatial distribution of weeds in arable crops: are current sampling and analytical methods appropriate? Weed Research, 41, 1-18.

Savage, D., M.J. Barbetti, W.J. Macleod, M.U. Salam, and M. Renton (2011), Can mechanistically parameterised, anisotropic dispersal kernels provide a reliable estimate of wind-assisted dispersal? Ecological Modelling, 222, 1673-1682.

Soons, M.B., G.W. Heil, R. Nathan, G.G. Katul (2004). Determinants of long-distance seed dispersal by wind in grasslands. Ecology, 85, 3056-3068.

Stokes, K., K. Ward, and M. Colloff (2010). Alterations in flood frequency increase exotic and native species richness of understorey vegetation in a temperate floodplain eucalypt forest. Plant Ecology, 211, 219233.

Thorpe, J.R., and R. Lynch (2000). The determination of weeds of national significance. Launceston, Tasmania, National Weeds Strategy Executive Committee. 234pp.

Travis, J.M.J., and C. Dytham (1998). The evolution of dispersal in a metapopulation: a spatially explicit, individual-based model. Proceedings of the Royal Society B-Biological Sciences, 265, 17-23.

Travis, J.M.J., H.S. Smith, and S.M.W. Ranwala (2010). Towards a mechanistic understanding of dispersal evolution in plants: conservation implications. Diversity and Distributions, 16, 690-702.

Truscott, A.M., C. Soulsby, C.F. Palmer, L. Newell, and P.E. Hulme (2006). The dispersal characteristics of the invasive plant Mimulus guttatus and the ecological significance of increased occurrence of high-flow events. Journal of Ecology, 94, 1080-1091.

Veldman, J.W., and F.E. Putz (2010). Long-distance Dispersal of Invasive Grasses by Logging Vehicles in a Tropical Dry Forest. Biotropica, 42, 697-703.

Weeds Australia (2003). Weed Management Guide - Parthenium weed (Parthenium hysterophorus). In: Weeds of National Significance. CRC Weed Management. Website: http://www.weeds.org.au/docs/parthenium_weed_mgt_guide.pdf. Accessed 21st July, 2011. 